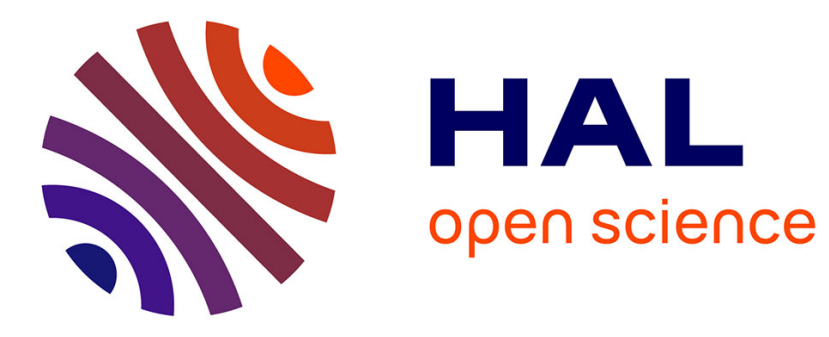

\title{
Reversibly crosslinked thermo- and redox-responsive nanogels for controlled drug release
}

\author{
Ji Liu, Christophe Detrembleur, Marie Hurtgen, Antoine Debuigne, \\ Marie-Claire de Pauw-Gillet, Stéphane Mornet, Etienne Duguet, Christine \\ Jérôme
}

\section{To cite this version:}

Ji Liu, Christophe Detrembleur, Marie Hurtgen, Antoine Debuigne, Marie-Claire de Pauw-Gillet, et al.. Reversibly crosslinked thermo- and redox-responsive nanogels for controlled drug release. Polymer Chemistry, 2014, 5 (1), pp.77-88. 10.1039/c3py00839h . hal-00923642

\section{HAL Id: hal-00923642 \\ https://hal.science/hal-00923642}

Submitted on 7 Jul 2015

HAL is a multi-disciplinary open access archive for the deposit and dissemination of scientific research documents, whether they are published or not. The documents may come from teaching and research institutions in France or abroad, or from public or private research centers.
L'archive ouverte pluridisciplinaire HAL, est destinée au dépôt et à la diffusion de documents scientifiques de niveau recherche, publiés ou non, émanant des établissements d'enseignement et de recherche français ou étrangers, des laboratoires publics ou privés. 


\title{
Reversibly-crosslinked Thermo- and Redox-responsive Nanogels for Controlled Drug Release $\dagger$
}

\author{
Ji Liu, ${ }^{a, c}$ Christophe Detrembleur, ${ }^{* a}$ Marie Hurtgen, ${ }^{a}$ Antoine Debuigne, ${ }^{a}$ Marie-Claire De Pauw-Gillet, ${ }^{b}$ \\ Stéphane Mornet, ${ }^{c}$ Etienne Duguet ${ }^{c}$ and Christine Jérôme*a
}

\begin{abstract}
Reversibly-crosslinked poly(vinyl alcohol)- $b$-poly( $N$-vinylcaprolactam) PVOH- $b$-PNVCL nanogels were prepared by using a redox-responsive crosslinking agent, 3,3'-dithiodipropionic acid (DPA), to crosslink the PVOH corona, above the lower critical solution temperature (LCST) of the PNVCL block. Stability of 10 the as-prepared cross-linked nanogels against heating and dilution with water was studied by dynamic light scattering (DLS) to follow the evolution of the hydrodynamic diameter and size distribution.

Stability under reductive condition was also studied with DLS and transmission electron microscopy (TEM) after exposure to dithiothreitol (DTT) buffer solutions at different $\mathrm{pH}$. Reversibility of the crosslinking was conducted by treating the de-crosslinked nanogels with hydrogen peroxide $\left(\mathrm{H}_{2} \mathrm{O}_{2}\right)$ above

15 the LCST. As a hydrophobic drug model, Nile red (NR) was loaded into the crosslinked nanogels, and triggered release behaviours were studied after exposure to the same DTT buffer solutions. Moreover, two PVOH- $b$-PNVCL copolymers with different compositions and LCST were used to evaluate the effect of LCST on the release behaviours of the crosslinked nanogels. Cytotoxicity of the crosslinked nanogels against mouse fibroblast-like L929 cell line was assessed via the MTS assay, and preliminary studies on

20 cellular uptake of the crosslinked nanogels within human melanoma MEL-5 cells was also carried out with fluorescence microscopy and fluorescence-activated cell sorting.
\end{abstract}

\section{Introduction}

Recently, considerable efforts were devoted to the development of novel drug delivery systems (DDS), ${ }_{25}$ which are expected to overcome the key therapeutical issues emerging in current clinical practices, such as poor intracellular delivery, lack of control over the release behaviours, significant side effects, etc. ${ }^{1,2}$ In the past few years, nano-sized polymer micelles have ${ }_{30}$ been suggested as promising vehicles for DDS due to their outstanding advantages in drug loading capacity and cellular uptake efficiency, as well as their nanoscaled dimension which can accomplish an enhanced permeability and retention (EPR) effect in tumour ${ }_{35}$ sites. $^{2-5}$ Generally, self-assembled micelles could be obtained from unimers above the critical micelle concentration (CMC); and when stimuli-responsive materials are used, release of the drug payloads could be triggered by external stimuli, such as light or 40 magnetic field application, reductive agents activation, variation in $\mathrm{pH}$, temperature or ionic strength, etc. - $^{4-7}$

However, the main drawback of these physicallyassembled micelles should be the incapacity to avoid premature release during the in vivo delivery routine. ${ }^{2,8}$ ${ }_{45}$ To circumvent this limitation, crosslinking strategies have been attempted. The covalently stabilized micelles, particularly shell crosslinked micelles, are attracting increasing attention. ${ }^{9}$ Various chemical reactions were attempted to crosslink the shell of those so physically-assembled micelles, such as carbodiimide coupling of carboxylic acid groups with diamines, ${ }^{10}$ coupling of hydroxyl groups with divinyl sulfone, ${ }^{11}$ UV-induced coupling of cinnamoyl groups, ${ }^{12}$ to cite only a few.

${ }_{55}$ These traditional covalently-crosslinked structures aimed for DDS application are always limited by a number of drawbacks, including poor solubility, low reactivity, toxicity and lack of control over the release behaviours due to the irreversible crosslinking ${ }_{60}$ structures, etc. ${ }^{4,6,13}$ An alternative approach involves the reversible crosslinking with disulfide bonds, which are redox-responsive and can be easily cleaved when exposed to some reductive reagents, such as dithiothreitol (DTT) or glutathione. It was reported ${ }_{65}$ that concentration of glutathione in the cytosol (10 $\mathrm{mM})$ is ca. $2 \sim 3$ orders higher than that in the extracellular fluids $(\mathrm{ca} .2 \sim 20 \mu \mathrm{M}){ }^{14,15}$ Thus, this specific feature might favour the cleavage of disulfide bonds responding to intracellular glutathione level, 70 and makes this kind of disulfide-crosslinked micelles more appealing for DDS. Up to now, some reversiblycrosslinked polymer micelles based on disulfide bonds have been reported for DDS and also triggered drug 
release. $^{13,16-24}$.

As far as we know, poly( $N$-vinylcaprolactam) (PNVCL) is one of the most recently studied thermoresponsive macromolecules with lower critical ${ }_{5}$ solution temperature (LCST) of $c a .32^{\circ} \mathrm{C}$. And change in temperature can cause the phase transition between hydrophobic and hydrophilic state. ${ }^{5}$ When involved in a block copolymer with another hydrophilic block, it results in the formation or dissociation of core/corona${ }_{10}$ structured micelles, driven by the change in temperatures. ${ }^{3-5}$ On the other side, poly(vinyl alcohol) (PVOH)-based micelles or hydrogels have also been extensively investigated as good candidates for DDS application, due to the hydrophilic essence and also ${ }_{15}$ excellent biocompatibility of $\mathrm{PVOH}$ block. ${ }^{25-28}$ Recently, we have reported the synthesis of welldefined PVOH- $b$-PNVCL copolymers with different compositions via the cobalt-mediated radical polymerization (CMRP) strategy, ${ }^{27,29,30}$ and ${ }_{20}$ dependence of LCST on chemical composition of the copolymers was also properly investigated. ${ }^{30} \mathrm{Up}$ to now, thermo-induced micelles from $\operatorname{poly}(N-$ isopropylacrylamide) PNIPAm or PNVCL-based amphiphilic copolymers, with a hydrophobic PNIPAm ${ }_{25}$ or PNVCL core and another hydrophilic block as corona above the LCST, have ever been widely reported. $^{18,}{ }^{31-34}$ In the case of PVOH- $b$-PNVCL copolymers, thermo-induced formation of micelles with $\mathrm{PVOH}$ corona was reported in our recent report. ${ }^{30}$

${ }_{30}$ However, due to their inferior stability against heating, inter-particles agglomeration occurred upon further heating above the LCST.

In this work, we report the synthesis and loading/release properties of the reversibly${ }_{35}$ crosslinked thermo- and redox-responsive nanogels based on PVOH- $b$-PNVCL copolymers (Scheme 1). 3,3'-dithiodipropionic acid (DPA) was used to crosslink the PVOH corona above the LCST of the PNVCL blocks; then crosslinked nanogels were ${ }_{40}$ obtained after cooling down below the volume phase transition temperature (VPTT) of the crosslinked structures. Stability of the corsslinked nanogels against heating and diluting with de-ionized water was evaluated with dynamic light scattering (DLS) ${ }_{45}$ technique. Stability of the crosslinked nanogels against reductive reagents was also studied with DLS after exposing to DTT buffer solution $(10 \mathrm{mM})$ with different $\mathrm{pH}$ values, while an oxidizing agent $\left(\mathrm{H}_{2} \mathrm{O}_{2}\right)$ was used to evaluate the reversibility of the ${ }_{50}$ crosslinking. Nile red (NR) was used as a hydrophobic drug model to study the triggered release behaviours under different conditions. Cytotoxicity of the crosslinked nanogels against the mouse fibroblast-like L929 cells was also evaluated via the MTS assay, and ${ }_{55}$ preliminary studies on cellular uptake of the crosslinked nanogels within human melanoma MEL-5 cells were finally investigated.

\section{Experimental Details}

\section{Materials}

${ }_{60}$ 3,3'-dithiodipropionic acid (DPA, 99\%), 1-ethyl-3-(3dimethylaminopropyl) carbodiimide (EDC, 98\%), Nile red (NR, 98\%), dithiothreitol (DTT, 99\%), 4dimethylaminopyridine (DMAP, 98\%), sodium phosphate dibasic $\left(\mathrm{Na}_{2} \mathrm{HPO}_{4}, 98.5 \%\right)$, potassium ${ }_{65}$ phosphate monobasic $\left(\mathrm{KH}_{2} \mathrm{PO}_{4}, 98 \%\right)$, sodium acetate trihydrate $\left(\mathrm{NaAc} \cdot 3 \mathrm{H}_{2} \mathrm{O}, 99.0 \%\right)$, acetic acid (HAc, $99 \%)$, sodium chloride $(\mathrm{NaCl}, 98 \%)$, potassium chloride $(\mathrm{KCl}, 99 \%)$, 4,6-diamidino-2-phenylindole (DAPI, 98\%) and hydrogen peroxide solution $\left(\mathrm{H}_{2} \mathrm{O}_{2}\right.$, $\left.{ }_{70} 30 w t . \%\right)$ were purchased from Aldrich. DMEM (1 g/L glucose), L-glutamine, PBS buffer solution $\left(\mathrm{Ca}^{2+}\right.$ and $\mathrm{Mg}^{2+}$ free), fetal bovine serum (FBS) and trypsin were obtained from BioWhittaker (Walkersville, MD). 3(4,5-dimethylthiazol-2-yl-5-(3-

${ }_{75}$ carboxymethoxyphenyl)-2-(4-sulfophenyl)-2Htetrazolium (MTS) was purchased from Promega (Madison, USA). PBS buffer solution (with $\mathrm{Ca}^{2+}$ and $\mathrm{Mg}^{2+}$ ), penicillin $\mathrm{G}$ and streptomycin were purchased from GIBCO BRL (Gaithersburg, MD).

PVOH- $b$-PNVCL copolymers were obtained by hydrolysis of poly(vinyl acetate)- $b$-poly $(N-$ vinylcaprolactam) copolymers (PVAc- $b$-PNVCL), prepared via CMRP strategy according to a previously reported procedure. ${ }^{30}$ The physico-chemical features ${ }_{85}$ of the PVOH- $b$-PNVCL copolymers used in this work were summarized in Table 1.

\section{Methods}

Preparation of PVOH- $b$-PNVCL crosslinked nanogels

PVOH- $b$-PNVCL shell crosslinked micelles were ${ }_{90}$ firstly prepared from the aqueous polymer solution above its LCST, and after the crosslinking reaction, the crosslinked nanogels were obtained upon cooling down below the VPTT of the crosslinked structures. Typically, the $\mathrm{PVOH}_{180}-b$-PNVCL 110 copolymer was ${ }_{95}$ dissolved in $20 \mathrm{~mL}$ of de-ionized water to obtain a polymer concentration of $0.05 w t . \%$ (i.e. $7.8 \times 10^{-5} \mathrm{~mol}$ $\mathrm{VOH}$ monomer units) before stirring and heating to $50^{\circ} \mathrm{C}$. Immediately, milky-white colloidal aggregates were detected upon heating, indicating the formation 100 of thermo-induced micelles. After equilibration at $50^{\circ} \mathrm{C}$ for $10 \mathrm{~min}$, DPA $\left(8.4 \mathrm{mg}, 3.9 \times 10^{-5} \mathrm{~mol}\right.$, molar ratio $\mathrm{DPA} / \mathrm{VOH}=1: 2), \mathrm{EDC}\left(12.0 \mathrm{mg}, 7.8 \times 10^{-5} \mathrm{~mol}\right)$ and DMAP $\left(11.4 \mathrm{mg}, 9.5 \times 10^{-5} \mathrm{~mol}\right)$ were added. After degassing by bubbling nitrogen for $20 \mathrm{~min}$, the mixture ${ }_{105}$ was stirred at $50^{\circ} \mathrm{C}$ for another $48 \mathrm{~h}$. Upon cooling down to room temperature, the mixture was dialyzed (cut-off: 3,500 g/mol) against de-ionized water for another $48 \mathrm{~h}$, in order to remove the free DPA, catalysts and by-products. White powders were ${ }_{110}$ obtained after freeze-drying.

Stability of the PVOH- $b$-PNVCL crosslinked nanogels and reversibility of the crosslinking

Stability of the PVOH- $b$-PNVCL crosslinked nanogels against swelling was investigated by diluting 
the crosslinked nanogels solution $(0.05 w t . \%)$ with deionized water at $25^{\circ} \mathrm{C}$. DLS measurement $\left(25^{\circ} \mathrm{C}\right)$ was used to follow the change in hydrodynamic diameters $\left(D_{\mathrm{h}}\right)$ and size distribution (PDI) after dilution. For each ${ }_{5}$ dilution period, the solution was kept for at least $1 \mathrm{~h}$ to reach the swelling equilibrium before characterization.

Stability of the PVOH- $b$-PNVCL crosslinked nanogels against heating was also studied by DLS with the crosslinked nanogels solution $(0.05 w t . \%)$ under ${ }_{10}$ gradual heating from 25 to $50^{\circ} \mathrm{C}$.

Stability of the PVOH- $b$-PNVCL crosslinked nanogels against reductive reagents was studied by exposing the crosslinked nanogels solution (0.05 $w t . \%)$ to $10-\mathrm{mM}$ DTT solution in different degassed 15 buffers, such as PBS (pH 7.4), PBS (pH 8.5) and $\mathrm{NaAc} / \mathrm{HAc}(\mathrm{pH} 4.5)$ buffers at $37^{\circ} \mathrm{C}$. At each predetermined interval, 1-mL nanogels solution were collected with a syringe for DLS measurement $\left(25^{\circ} \mathrm{C}\right)$, in order to monitor the change in $D_{\mathrm{h}}$ and PDI. After 24${ }_{20} \mathrm{~h}$ treatment, the mixture was cooled down and dialyzed (cut-off: 3,500 g/mol) against de-ionized water at room temperature for another $48 \mathrm{~h}$. The purified decrosslinked (DCL) nanogels solution was freeze-dried and white powders were obtained.

${ }_{25}$ Reversible crosslinking (RCL) of the PVOH- $b$ PNVCL DCL nanogels was conducted by adding $1 \mathrm{~mL}$ of hydrogen peroxide solution $(30 w t . \%)$ into $10 \mathrm{~mL}$ of DCL nanogels solution $(0.05 w t . \%)$ at $50^{\circ} \mathrm{C}$ and then stirred overnight. RCL nanogels white powders 30 were obtained after freeze-drying.

Model studies of guest loading and triggered release

Nile red, a hydrophobic drug model, was loaded into the PVOH- $b$-PNVCL crosslinked nanogels in order to monitor the redox-triggered release behaviours with a ${ }_{35}$ fluorometer. Herein, after the thermo-induced formation of PVOH- $b$-PNVCL micelles at $50^{\circ} \mathrm{C}, 2 \mathrm{~mL}$ of NR solution in THF $(0.2 \mathrm{mg} / \mathrm{mL})$ were added, and then the mixture was stirred for another 30 min in dark, at the end of which the THF solvent was supposed to ${ }_{40}$ be fully evaporated. The crosslinking reaction was carried out according to the above-mentioned protocol. The non-encapsulated NR was removed by filtration $(0.8 \mu \mathrm{m})$, and other free DPA and by-products were removed via dialysis against de-ionized water in dark.

To study the release profiles, $10 \mathrm{~mL}$ of the NRloaded PVOH- $b$-PNVCL crosslinked nanogels solution $(0.05 w t . \%)$ were put in a dialysis bag (cutoff: $3,500 \mathrm{~g} / \mathrm{mol}$ ), and then dialyzed against $200 \mathrm{~mL}$ of DTT-contained $(10 \mathrm{mM})$ buffer solutions with ${ }_{50}$ different $\mathrm{pH}$ values, under gentle stirring at $37^{\circ} \mathrm{C}$. The release behaviours in buffer solutions (no DTT) with different $\mathrm{pH}$ values were taken for comparison. At each predetermined interval, $0.2 \mathrm{~mL}$ of the supernatant nanogels solution was withdrawn from the dialysis bag

${ }_{55}$ (released NR precipitated into the bottom of the dialysis bag) for fluorescence measurement at $37^{\circ} \mathrm{C}$, in order to estimate the retained amount of NR. Cumulative release of NR was calculated according to the formula:

$$
R=\frac{I_{0}-I_{\mathrm{t}}}{I_{0}} \times 100 \%
$$

where $I_{0}$ was denoted as the fluorescence intensity of NR-loaded crosslinked nanogels solution $(0.05 w t . \%)$ before release, while $I_{\mathrm{t}}$ the fluorescence intensity of supernatant nanogels solution at a specific sampling ${ }_{65}$ time during the release experiments.

Cell culture and cytotoxicity against fibroblast-like L929 cells The mouse fibroblast-like L929 cells (ATCC CCL-1) were grown for $24 \mathrm{~h}$ at $37^{\circ} \mathrm{C}$ under humidified air $(5$ vol.\% of $\mathrm{CO}_{2}$ ) in DMEM medium, which was 70 supplemented with 5 vol.\% of FBS, 1 vol.\% of glutamax, 1 vol. $\%$ of penicillin/streptomycin $(10,000$ units of penicillin (base) and 10,000 units of streptomycin (base)/mL) before use (DMEM complete medium). The human melanoma MEL-5 cell line ${ }_{75}$ (originated from a non-pigmented clone 32, gift from Dr. G. Degiovanni, University of Liège) was also cultured in DMEM complete medium for $24 \mathrm{~h}$. After rinsing with PBS $\left(\mathrm{Ca}^{2+} / \mathrm{Mg}^{2+}\right.$ free $)$ buffer solution, the cells were detached with trypsin $(0.2$ vol.\% $) / \mathrm{PBS}$ ${ }_{80}\left(\mathrm{Ca}^{2+} / \mathrm{Mg}^{2+}\right.$ free $)$ buffer solution.

Cytotoxicity measurements were carried out with the L929 cell line. The cells were first seeded in 96well plates at a density of $5 \times 10^{3}$ cells/well and grown in DMEM complete medium for $24 \mathrm{~h}$. Cells were then ${ }_{85}$ treated with PVOH- $b$-PNVCL crosslinked nanogels in DMEM complete medium with different concentrations $(2,1,0.5$ and $0.25 \mathrm{mg} / \mathrm{mL})$ for 24 and 48 h. For each concentration, five parallel measurements were carried out at the same time. After ${ }_{90}$ each incubation period, the cells were rinsed with PBS (with $\mathrm{Ca}^{2+} / \mathrm{Mg}^{2+}$ ) buffer solution, and cell viabilities were evaluated via the MTS assay. Specifically, $20 \mu \mathrm{L}$ of MTS and $100 \mu \mathrm{L}$ of PBS (with $\mathrm{Ca}^{2+} / \mathrm{Mg}^{2+}$ ) buffer solution were added for each well, and then the plates ${ }_{95}$ were incubated at $37^{\circ} \mathrm{C}$ for $30 \mathrm{~min}$. The absorbance at $490 \mathrm{~nm}$ was measured by using a Power wave $\mathrm{X}$ (Biotek instrument Inc.) micro-plate reader. Percentage cell viabilities were determined relative to the untreated cells (control, $100 \%$ viability).

${ }_{100}$ Cellular uptake into human melanoma MEL-5 cells

Qualitative studies of the cellular uptake with fluorescence microscopy were carried out with the treated MEL-5 cells after internalizing with NRuploaded PVOH- $b$-PNVCL crosslinked nanogels. ${ }_{105}$ MEL-5 cells $\left(3.8 \times 10^{5}\right)$ were seeded in a 12 -well plate within $2 \mathrm{~mL}$ of DMEM complete medium. After 24-h incubation, the culture medium was replaced with 2 $\mathrm{mL}$ of fresh DMEM complete medium (blank) or NRloaded crosslinked nanogels in DMEM complete ${ }_{110}$ medium $(1.0,0.5,0.25$ or $0.1 \mathrm{mg} / \mathrm{mL})$, respectively. After incubating for a predetermined period $(3,6,15$ or $24 \mathrm{~h}$ ), the medium was removed and the cells were rinsed twice with PBS buffer $\left(\mathrm{Ca}^{2+} / \mathrm{Mg}^{2+}\right.$ free $)$ to remove the free nanogels. Then the cells were treated 115 with paraformaldehyde (4 vol.\%)/DAPI $(1 \mathrm{vol} . \%) / \mathrm{PBS}$ buffer solution (with $\mathrm{Ca}^{2+} / \mathrm{Mg}^{2+}$ ) at room temperature 
for $15 \mathrm{~min}$ in dark. After rinsing with PBS buffer solution (with $\mathrm{Ca}^{2+} / \mathrm{Mg}^{2+}$ ) for two times, $2 \mathrm{~mL}$ of PBS buffer solution (with $\mathrm{Ca}^{2+} / \mathrm{Mg}^{2+}$ ) were added. Analysis of the treated cells was performed with an Olympus 5 IX81 inverted fluorescence microscope.

Quantitative studies on the cellular uptake of NRuploaded PVOH- $b$-PNVCL crosslinked nanogels within MEL-5 cells were conducted with a FACScan fluorescence-activated cell sorter (FACS canto II, ${ }_{10}$ Becton-Dickinson). MEL-5 cells internalized with the NR-uploaded crosslinked nanogels were obtained according to the above-mentioned protocol. After the cells were detached with trypsin $(0.2$ vol. $\%) / \mathrm{PBS}$ $\left(\mathrm{Ca}^{2+} / \mathrm{Mg}^{2+}\right.$ free) buffer solution, centrifuged $(1,300$ $\left.{ }_{15} \mathrm{rpm}, 5 \mathrm{~min}\right)$, and re-dispersed in fresh PBS $\left(\mathrm{Ca}^{2+} / \mathrm{Mg}^{2+}\right.$ free) buffer solution. $400 \mu \mathrm{L}$ of the treated MEL-5 cells suspension $\left(5 \times 10^{5}\right.$ cells $\left./ \mathrm{mL}\right)$ were used for the FACS measurement. Fluorescence intensities and the percentage of cell-associated fluorescence were ${ }_{20}$ determined by using the CellQuest software. The ratio of the fluorescence intensity per 10,000 treated cells to that of 10,000 untreated cells was expressed as mean fluorescence intensity (MFI). The bar graphs in the figures represent mean values ( \pm standard deviation)

${ }_{25}$ from three independent experiments.

Statistical analysis

Cell culture experiments were performed in triplicate. Results were all presented as mean value ( \pm standard deviation). Statistical analyses of the data were 30 performed using the unpaired and two-tailed Student's $t$-test. Statistical significance was determined at $p<$ 0.05 .

\section{Characterization}

Raman spectra of the PVOH- $b$-PNVCL crosslinked ${ }_{35}$ nanogels samples and the parent PVOH- $b$-PNVCL block copolymers after freeze-drying were recorded using a LabRam spectrometer, equipped with an Olympus confocal microscope and a liquid nitrogencooled open-electrode detector $(1024 \times 256 \mathrm{CCD})$. An ${ }_{40}$ argon-ion laser with emission wavelength at $514.5 \mathrm{~nm}$ and power of $100 \mathrm{~mW}$ were used. All measurements were integrated within $50 \mathrm{~s}$.

Dynamic light scattering (DLS) measurements were carried out with a Malvern Instrument Nano-ZS, ${ }_{45}$ which was equipped with a He-Ne laser $(\lambda=663 \mathrm{~nm})$ and scattering angle of $90^{\circ}$. The correlation function was analysed via the CONTIN method, and $D_{\mathrm{h}}$ was determined by using the Stokes-Einstein equation. The averaged $D_{\mathrm{h}}$ was obtained from three different runs. ${ }_{50}$ Standard deviation was used to evaluate the size polydispersity index (PDI). Every measurement was carried out with a PVOH- $b$-PNVCL crosslinked nanogels or the parent PVOH- $b$-PNVCL polymer solution with a fixed concentration of $0.05 \mathrm{wt} . \%$.

${ }_{55}$ Transmission electron microscopy (TEM) was used to measure the size of the PVOH- $b$-PNVCL crosslinked nanogels and analyse their morphology with a Philips CM-100 microscope. A drop of the nanogels solution was placed onto a carbon-coated ${ }_{60}$ copper grid and left to dry under air before observation. The size distribution and average size was obtained by sampling $c a$. 100 particles on the TEM images.

Scanning electron microscopy (SEM) was used to ${ }_{65}$ study the surface of the PVOH- $b$-PNVCL crosslinked nanogels with a JSM 840A microscope at $4 \mathrm{kV}$ in high vacuum conditions. A drop of nanogels solution ( 0.05 $w t . \%)$ was deposited on a glass substrate, and dried overnight at RT under air. Then the sample was ${ }_{70}$ sputtered with gold in a cathode evaporator under argon atmosphere before observation.

Turbidimetry measurement of the PVOH- $b$-PNVCL crosslinked nanogels or the parent PVOH- $b$-PNVCL polymer solutions $(0.05 \mathrm{wt} . \%)$ was carried out with a ${ }_{5} \mathrm{Hitachi}$ U-3300 spectrophotometer from 25 to $50^{\circ} \mathrm{C}$ at a heating rate of $1^{\circ} \mathrm{C} / \mathrm{min}$. Transmittance at $700 \mathrm{~nm}$ was plotted against the temperature, and LCST was defined as the temperature where transmittance started to decrease.

${ }_{80}{ }^{1} \mathrm{H}$ Nuclear magnetic resonance (NMR) spectra of the PVOH- $b$-PNVCL DCL nanogels or parent PVOH$b$-PNVCL polymer were recorded with a $250 \mathrm{MHz}$ Bruker spectrometer in DMSO- $d_{6}$ at $353 \mathrm{~K}$.

Fluorescence spectra of the NR-loaded PVOH- $b$ ${ }_{85}$ PNVCL crosslinked nanogels solution or NR solutions were recorded at $37^{\circ} \mathrm{C}$ using a LS-55 Perkin Elmer fluorometer at emission wavelength of $595 \mathrm{~nm}$ (exciting wavelength of $485 \mathrm{~nm}$ ). For each measurement, the nanogels concentration was fixed at ${ }_{90} 0.05 w t . \%$.

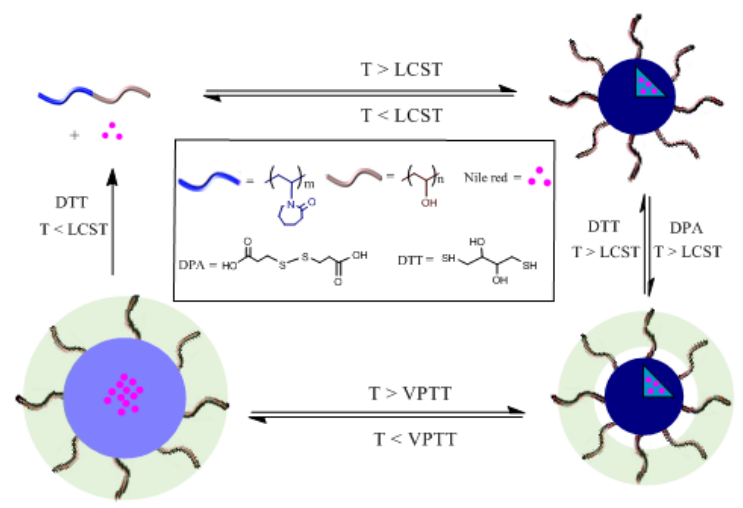

Scheme 1 Schematic illustration of the preparation, dissociation of PVOH$b$-PNVCL crosslinked nanogels, loading of Nile red and redox-triggered release behaviours (LCST: lower critical solution temperature, VPTT: 95 volume phase transition temperature)

\section{Results and discussion}

\section{Preparation of the crosslinked nanogels}

Similarly to PNIPAm, PNVCL homopolymer could also dissolve in cold and dilute aqueous medium; 100 however, it becomes insoluble above $c a .32^{\circ} \mathrm{C}$ due to its thermo-induced hydrophilic/hydrophobic phase transition around its LCST. ${ }^{5}$ The value of this LCST is highly dependent on the concentration and chain 
length of PNVCL. In the case of copolymers, the nature, content and block length of the second comonomer might also affect the LCST. Generally, the lower the content, the shorter length of the thermo${ }_{5}$ responsive block, the higher the LCST. ${ }^{35-37}$ In order to tune the LCST of PNVCL block above the human body temperature $\left(37^{\circ} \mathrm{C}\right)$, hydrophilic $\mathrm{PVOH}$ block was chosen, and block copolymers of PVOH- $b$ PNVCL were prepared via cobalt-mediated radical ${ }_{10}$ polymerization $^{29,38}$ following our previous report. ${ }^{30}$ Briefly, a poly(vinyl acetate) macroinitiator endcapped with $\mathrm{Co}(\mathrm{acac})_{2}$ was prepared in the bulk using an alkyl-Co(acac $)_{2}$ initiator at $40^{\circ} \mathrm{C}$. Then, the polymerization of $N$-vinylcaprolactam (NVCL) 15 monomers was initiated by this macroinitiator in DMF at $40^{\circ} \mathrm{C}$ to synthesize PVAc- $b$-PNVCL copolymers. Methanolysis of the PVAc block in the presence of potassium hydroxide led to the corresponding PVOH$b$-PNVCL block copolymers.

${ }_{20}$ As reported in our previous work, ${ }^{30}$ above the LCST of the PNVCL block, the collapsed hydrophobic PNVCL block formed the core of the thermo-induced micelles, while the PVOH block formed the hydrophilic corona. However, these physically ${ }_{25}$ assembled micelles were not stable against heating, and inter-micellar agglomeration was observed when the temperature was further increased above the LCST. Furthermore, dissociation into unimers occurred when temperature was decreased below the ${ }_{30}$ LCST. Herein, 3,3-dithiodipropionic acid (DPA; Scheme 1) is used to crosslink the PVOH corona above the LCST. And after cooling down below the VPTT, the PNVCL block becomes hydrophilic, and nanogels are obtained due to the presence of crosslinking. ${ }_{35}$ Additionally, the presence of disulfide bonds in the crosslinker also makes it possible to de-crosslink the nanogels with a reducing agent, such as dithiothreitol (DTT). Thus, if some drugs are loaded within the crosslinked nanogels, upon the DTT-treatment below ${ }_{40}$ the LCST of PNVCL blocks, the crosslinked nanogels could dissociate into unimers, thereby triggered release is achieved (Scheme 1). However, upon the DTT-treatment above the LCST of PNVCL blocks, the micellar structures would remain intact, and the drugs 45 could be still retained within the micellar structure, even with the crosslinking structures are dissociated. Here, two different PVOH- $b$-PNVCL copolymers, one with LCST at human body temperature $\left(37^{\circ} \mathrm{C}\right)$ and the other above it $\left(41^{\circ} \mathrm{C}\right)$, are used (parameters listed in ${ }_{50}$ Table.1), in order to exploit the effect of LCST of the PVOH- $b$-PNVCL copolymers on the subsequent redox-triggered release behaviours.

After purification of the PVOH- $b$-PNVCL crosslinked nanogels via dialysis, Raman spectroscopy ${ }_{55}$ was used to confirm the crosslinking reaction with the presence of the S-S stretching vibration at $514 \mathrm{~cm}^{-1}$, which is typical for the disulfide bonds in the crosslinker (Fig. 1). Morphology of the crosslinked nanogels was studied with TEM, and approximately ${ }_{60}$ spherical crosslinked nanogels were observed, within the size range of $45 \sim 95$ and $70 \sim 110 \mathrm{~nm}$ for AM01 (Fig. 2a) and AM02 (Fig. 2b), respectively. The morphology was also confirmed with SEM technique, as shown in the representative SEM images of sample ${ }_{65}$ AM01 (See ESI, Fig. S1a and S1b†). Dynamic light scattering (DLS) measurements allowed to determine the hydrodynamic diameters of the nanogels at $25^{\circ} \mathrm{C}$, which are $280 \mathrm{~nm}(\mathrm{PDI}=0.17)$ and $460 \mathrm{~nm}(\mathrm{DPI}=$ 0.21 ) for AM01 and AM02, respectively. The larger ${ }_{70}$ size observed for AM02 than AM01 could be attributed to longer

Table 1 Macromolecular parameters of PVOH- $b$-PNVCL used in this study, and characteristics of the corresponding crosslinked nanogels, loaded or not with Nile Red (NR)

\begin{tabular}{|c|c|c|c|c|c|c|c|}
\hline \multirow[t]{2}{*}{ Sample } & \multicolumn{3}{|c|}{ PVOH- $b$-PNVCL } & \multicolumn{2}{|c|}{ crosslinked nanogels at $25^{\circ} \mathrm{C}$} & \multicolumn{2}{|c|}{ NR@crosslinked nanogels at $25^{\circ} \mathrm{C}$} \\
\hline & structure & PDI & $\operatorname{LCST}^{\mathrm{a}} /{ }^{\circ} \mathrm{C}$ & $D_{\mathrm{h}} / \mathrm{nm}$ & PDI & $D_{\mathrm{h}} / \mathrm{nm}$ & PDI \\
\hline AM01 & $\mathrm{PVOH}_{180}-b-\mathrm{PNVCL}_{110}$ & 1.06 & 41 & 280 & 0.17 & 300 & 0.22 \\
\hline
\end{tabular}




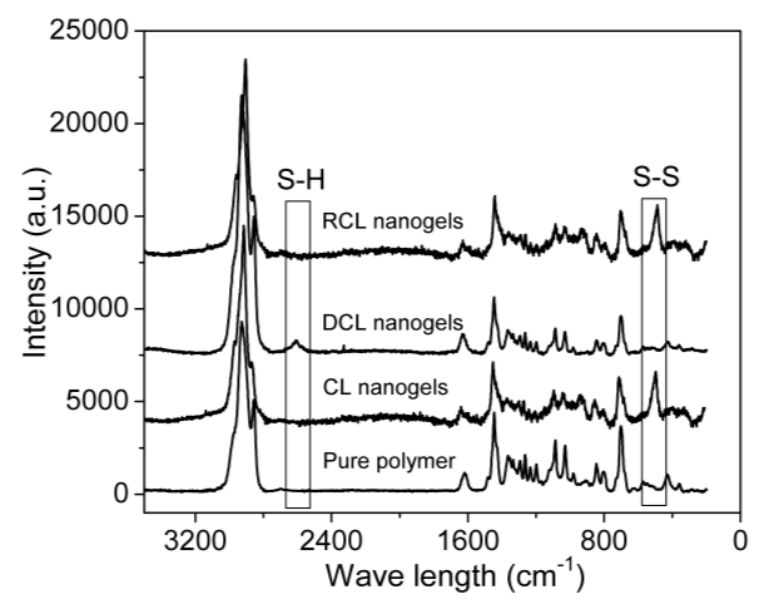

Fig. 1 Raman spectra of $\mathrm{PVOH}_{180}-b$ - $\mathrm{PNVCL}_{110}$ copolymer, crosslinked (CL) nanogels AM01, de-crosslinked (DCL) nanogels and re-crosslinked (RCL) nanogels.

s chain length, especially the PNVCL block in their parent polymers. The large difference between sizes from DLS and TEM analyses results from the fact that TEM images were taken when the crosslinked nanogels were in a dry and collapsed state, while 10 aqueous and swelled states for DLS analysis.

Thermo-responsiveness of the PVOH- $b$-PNVCL crosslinked nanogels and the parent block copolymers were evaluated and compared by turbidimetry. In Fig. $3 \mathrm{a}$, the transmittance of the two aqueous solutions $15\left(0.05 w t . \%\right.$ of $\mathrm{PVOH}_{180}-b-\mathrm{PNVCL}_{110}$ or of the corresponding crosslinked nanogels AM01) at $700 \mathrm{~nm}$ was plotted as a function of temperature from 25 to $50^{\circ} \mathrm{C}$. In the case of $\mathrm{PVOH}_{180}-b-\mathrm{PNVCL}_{110}$, the aqueous solution became milky-white and the 20 transmittance dropped sharply to zero when the temperature was increased to $c a .41^{\circ} \mathrm{C}$, higher than the LCST of PNVCL homopolymer of similar molar mass (ca. $32^{\circ} \mathrm{C}$ ), in agreement with the theory that introduction of another hydrophilic block results in a ${ }_{25}$ higher LCST. ${ }^{28,29}$ However, for the corresponding crosslinked nanogels AM01 solution (0.05 wt.\%), negligible decrease in transmittance was observed even above $44^{\circ} \mathrm{C}$. This could be attributed to the restricted mobility of the PNVCL block after ${ }_{30}$ crosslinking. The same phenomenon was also detected for crosslinked nanogels AM02 made of the $\mathrm{PVOH}_{226}$ $b$-PNVCL 494 copolymer with LCST of $37^{\circ} \mathrm{C}$ (See ESI, Fig. S2a $\dagger$ ).

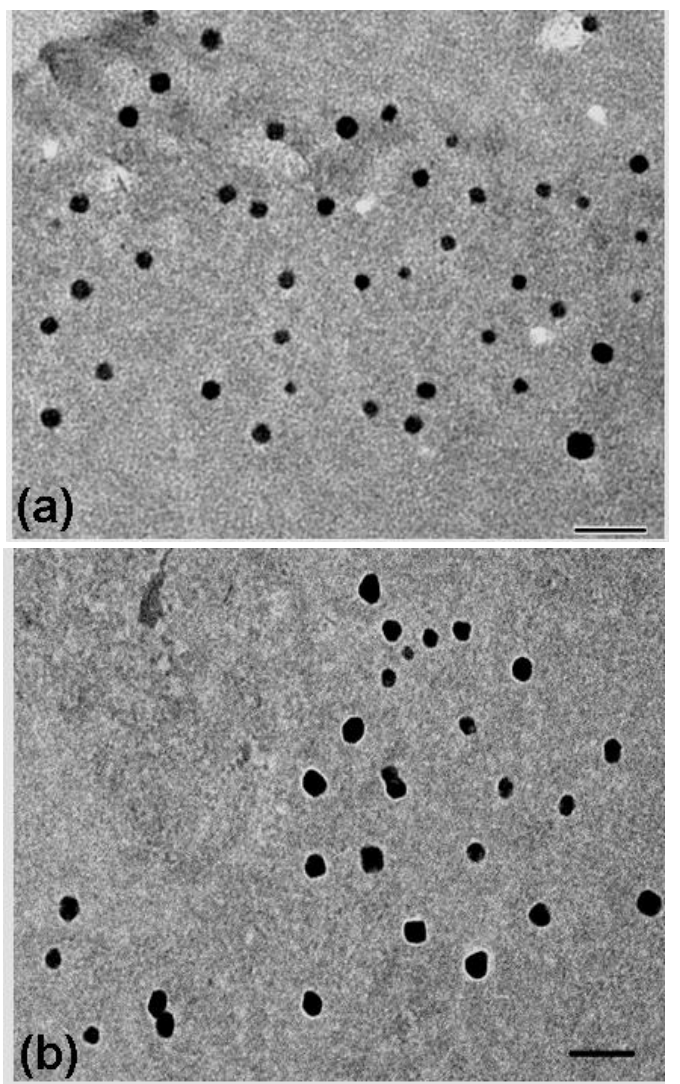

Fig. 2 TEM images of the crosslinked nanogels AM01 (a) and AM02 (b) (scale bar: $200 \mathrm{~nm}$ ).

DLS was used as another method to study the ${ }_{40}$ thermo-responsiveness and stability against heating of the PVOH- $b$-PNVCL crosslinked nanogels. Here, $D_{\mathrm{h}}$ and PDI of the $\mathrm{PVOH}_{180}-b$ - $\mathrm{PNVCL}_{110}$ polymer solution and the corresponding AM01 nanogels solution $(0.05 \mathrm{wt} . \%)$ was recorded under different ${ }_{45}$ temperatures. As shown in Fig. 3b, particles were detected below the VPTT in the nanogels solution, but none for the polymer solution. Upon further heating, thermo-induced micelles could be detected above $39^{\circ} \mathrm{C}$ for the polymer solution. However, unlike the ${ }_{50}$ polymer solution, neither inter-micellar aggregation nor increase in $D_{\mathrm{h}}$, but slight decrease in $D_{\mathrm{h}}$ was observed for the crosslinked nanogels when temperature increased further, indicating a superior resistance of the crosslinked nanogels to inter-particles ${ }_{55}$ agglomeration above the VPTT after crosslinking. Moreover, the same behaviour was observed for the aqueous solution of $\mathrm{PVOH}_{226}-b$ - $\mathrm{PNVCL}_{494}$ and its corresponding crosslinked nanogels AM02 (See ESI, Fig. S2b†). 

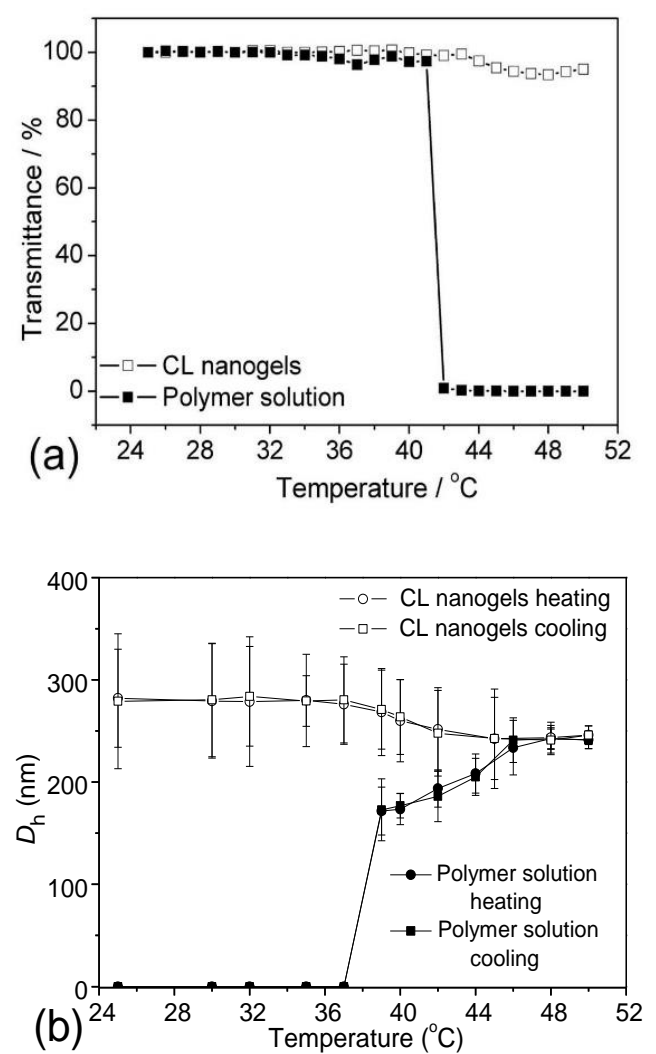

Fig. 3 Dependence of transmittance at $700 \mathrm{~nm}$ on temperature for the $\mathrm{PVOH}_{180}-b$-PNVCL ${ }_{110}$ solution (solid) and crosslinked (CL) nanogels 5 AM01 aqueous solution (open) $(0.05 w t . \%)$ (a), and plotting of $D_{\mathrm{h}}$ with size distribution against temperature for the $\mathrm{PVOH}_{180}-b$ - $\mathrm{PNVCL}_{110}$ (solid) and crosslinked (CL) nanogels AM01 aqueous solution (open) (0.05 wt.\%) during heating and cooling procedures (b). The solid lines just serve as eye guidance.

${ }_{10}$ It is important to note that the average sizes for the non-crosslinked and crosslinked nanogels (AM01) at $50^{\circ} \mathrm{C}$ were found to be similar: $240 \mathrm{~nm}(\mathrm{PDI}=0.04)$ against $250 \mathrm{~nm}(\mathrm{PDI}=0.06)$ ) in the size distribution diagrams in Fig. 4. The same observation was made on is the scattering intensities, which are proportional to the concentration of crosslinked nanogels. Moreover, for the crosslinked nanogels, after cooling down to $25^{\circ} \mathrm{C}$ from the shell crosslinked micelles $(240 \mathrm{~nm})$ at $50^{\circ} \mathrm{C}$, the size distribution diagram slightly shifted to the 20 right $(290 \mathrm{~nm})$, due to the phase transition and rearrangement of PNVCL block below the VPTT. The presence of nanogels below LCST of the PNVCL blocks could evidence a robust crosslinking within the as-prepared nanogels, compared with unimers ${ }_{25}$ obtained from the polymer solution upon cooling from 50 to $25^{\circ} \mathrm{C}$. On the other side, for an idealist nanogelsbased vehicles targeted for DDS application, it is indispensable to possess a short-term stability but also a long-term stability, and a slight change in size ${ }_{30}$ distribution diagram was observed after 3-month storage at room temperature for the AM01sample (See ESI, Fig. S3†).

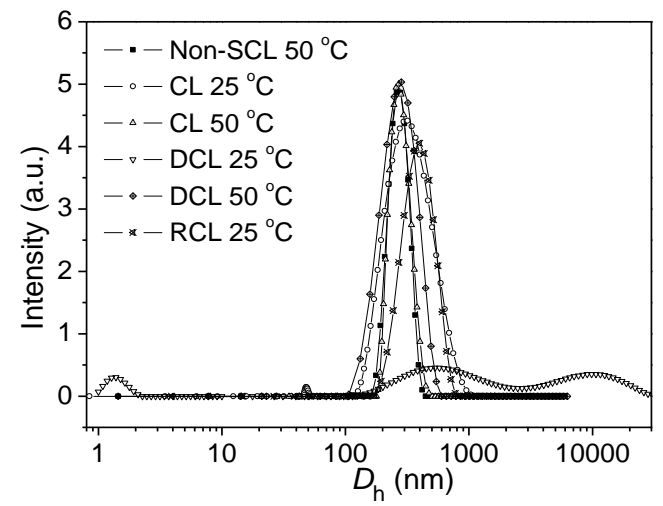

Fig. 4 Size distribution diagrams of the crosslinked nanogels AM01 35 aqueous solution $(0.05 w t . \%)$ under different conditions from DLS analysis: non-crosslinked nanogels (polymer solution) at $50^{\circ} \mathrm{C}$, crosslinked (CL) nanogels at 25 and $50^{\circ} \mathrm{C}$, de-crosslinked (DCL) nanogels at $25^{\circ} \mathrm{C}$, and re-crosslinked (RCL) nanogels at $25^{\circ} \mathrm{C}$. The solid lines just serve as eye guidance.

\section{${ }_{40}$ Stability of the nanogels and reversibility of the crosslinking}

It is of great importance for drug vehicles to remain stable during the delivery so that they can efficiently trap the drug payloads until they arrive to the desirable sites. Studies on the stability of crosslinked micelles or ${ }_{45}$ nanogels against different solvents were previously reported to evaluate their stability as DDS. . $^{19,39-41}$ Herein, the stability of the crosslinked nanogels AM01 against diluting was studied by following the change in $D_{\mathrm{h}}$ when diluted with de-ionized water below the ${ }_{50}$ VPTT; while studies on the swelling process were conducted by mixing equal volume of the crosslinked nanogels aqueous solution $(0.05 w t . \%)$ and de-ionized water. Change in $D_{\mathrm{h}}$ and PDI was measured by DLS and plotted against the swelling period (Fig. 5a). ${ }_{55}$ Similar to other crosslinked systems, ${ }^{39,40}$ slight and lagged swelling was observed against water dilution, indicating a good stability against swelling due to the presence of crosslinking. Additionally, the effect of dilution times on the swelling behaviour of AM01 was ${ }_{60}$ also investigated with the size distribution diagrams recorded in Fig. 5b. For each dilution time, the mixture was kept for another one hour to ensure the swelling equilibrium was reached. Slight right-shift of the size distribution patterns was observed with an increase in ${ }_{65}$ average size from 290 to $360 \mathrm{~nm}$ (1/4 vol. dilution), indicating the crosslinked nanogels experienced a relative mild swelling. Moreover, the size distribution becomes broader, and the swelling was restrained upon further dilution. All these results indicate a 70 neither compact nor rigid crosslinking is accomplished for the as-prepared nanogels; and this slight swelling against dilution is critical to the success of zero premature drug release upon intravenous injection, as compared to those of non-crosslinked micelle systems. 

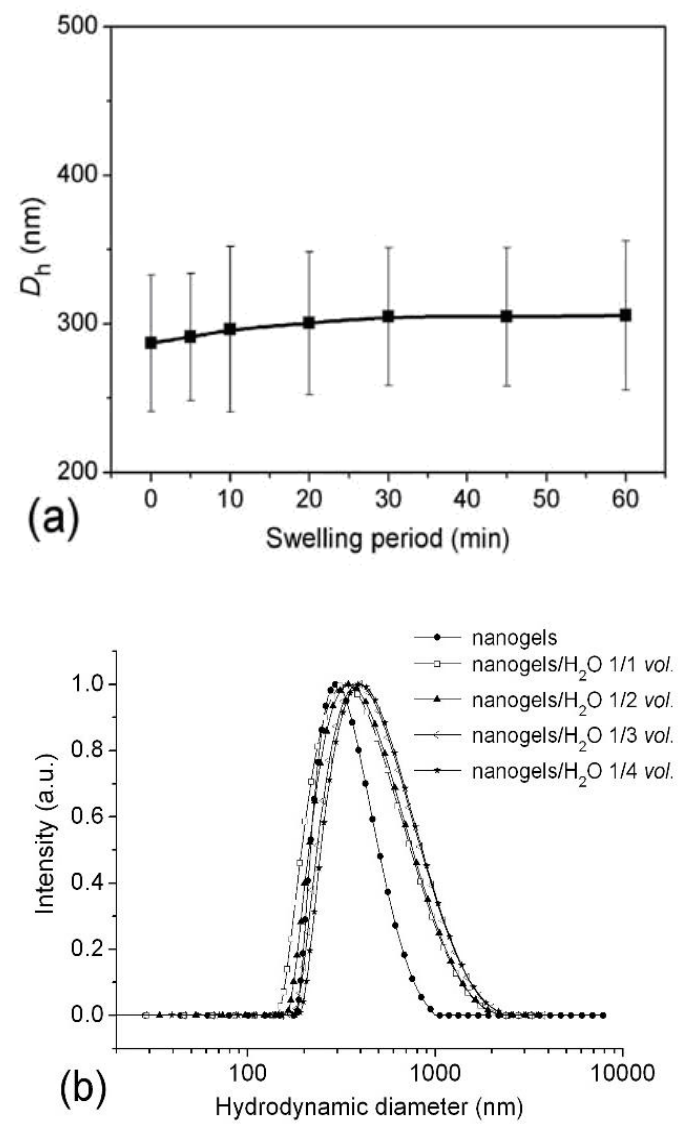

Fig. 5 Dependence of $D_{\mathrm{h}}$ and PDI of the crosslinked nanogels AM01 aqueous solution $(0.05 w t . \%)$ on the swelling period after equal-volume 5 water was added (a), normalized size distribution diagrams of the nanogels AM01 aqueous solution $(0.05 w t . \%)$ under different dilution times (nanogels solution $/ \mathrm{H}_{2} \mathrm{O}$, vol.) at $25^{\circ} \mathrm{C}(\mathrm{b})$. The solid lines just serve as eye guidance.

As far as we know, the disulfide bonds could be easily ${ }_{10}$ dissociated upon exposure to some reductive reagents, such as glutathione or dithiothreitol (DTT) under a mild basic condition, through the well-established thiol-disulfide exchange reaction. ${ }^{4,6}$ Although the concentration of glutathione, which is naturally ${ }_{15}$ present in the cytoplasm, is very low (mM-scale), it is still high enough to cleave the disulfide bonds. ${ }^{17,42}$ As previously reported, the most favourable reductive environment for DTT is under basic conditions. ${ }^{43}$ Herein, the stabilities of the crosslinked nanogels ${ }_{20}$ AM01 against different DTT $(10 \mathrm{mM})$ buffer solutions at $\mathrm{pH}$ values of 7.4 (serum condition), 8.5 (pancreatic condition) and 4.5 (lysosome condition) were also studied by DLS and summarized in Fig. 6a. As expected, the amount of nanogels (qualitatively probed ${ }_{25}$ by the intensity of the scattered light) decreased much more rapidly at $\mathrm{pH}$ of 8.5 than acidic conditions. In contrast, in the absence of DTT, nanogels remained stable over the experiment period (See ESI, Fig. S4a and $\mathrm{S} 4 \mathrm{~b} \dagger$ ). Fig. $6 \mathrm{~b}$ summarizes the variation of $D_{\mathrm{h}}$, PDI ${ }_{30}$ and scattering intensity at different period of the DTTtreatment $\left(10 \mathrm{Mm}\right.$ DTT, $\mathrm{pH} 8.5$ and $\left.37^{\circ} \mathrm{C}\right)$. It was found that $D_{\mathrm{h}}$ increased from 290 to $1850 \mathrm{~nm}$ (size distribution diagram in Fig 4) while scattering intensity decreased from 5.2 to 0.5 after 24 -h DTT ${ }_{35}$ treatment. Very few nanogels might be left after the DTT-treatment, which may be explained by that disulfide bonds were not completely cleaved and/or the re-oxidation of some thiol groups into disulfide bonds occurred during the sampling or dialysis ${ }_{40}$ process. Furthermore, similar to the report of Kataoka, ${ }^{17,44}$ due to the non-uniform cleavage of disulfide bonds, the crosslinked nanogels might experience a dramatic swelling, and here an increase in PDI was also observed from 0.2 to 0.8 , which was ${ }_{45}$ also evidenced in the size distribution diagram in Fig. 4. Moreover, presence of the peak in the range of 1 $2 \mathrm{~nm}$ for DCL nanogels at $25^{\circ} \mathrm{C}$ could be ascribed to the free unimers after de-crosslinking. The dissociation of the crosslinked nanogels was also ${ }_{50}$ confirmed by the TEM image of DCL nanogels samples after 24-h DTT treatment. In fact, it took us a long time to find nanogels particles on the TEM grid, and a particle with large size of $c a .500 \mathrm{~nm}$ was presented in ESI, Fig. S5a $\uparrow$, in agreement with the size ${ }_{55}$ distribution of DCL nanogels in Fig. 4 and $D_{\mathrm{h}}$ value in Fig. 6b. However, when taking the number-averaged distribution diagrams into consideration, as shown in ESI, Fig. S5b $\dagger$, strong signals in the range of $1 \sim 2 \mathrm{~nm}$ was detected for DCL nanogels, which could be ${ }_{60}$ assigned to the presence of free macromolecules, compared with the signals appearing in the size range of $100 \sim 300 \mathrm{~nm}$ for the crosslinked nanogels. These results would corroborate that almost all the nanogels were disintegrated into unimers, even with very few ${ }_{65}$ swelling nanogels left. The DCL nanogels were then analysed with ${ }^{1} \mathrm{H}$ NMR spectrometer. As shown in ESI, Fig. S5c $\dagger$, compared with parent $\mathrm{PVOH}-b$ PNVCL copolymer, new proton signals from the pendant $-(\mathrm{O}) \mathrm{COCH}_{2} \mathrm{CH}_{2} \mathrm{SH}$ group could be detected, ${ }_{70}$ and a DPA conversion of $\mathrm{ca} .10 \%$ was roughly estimated.

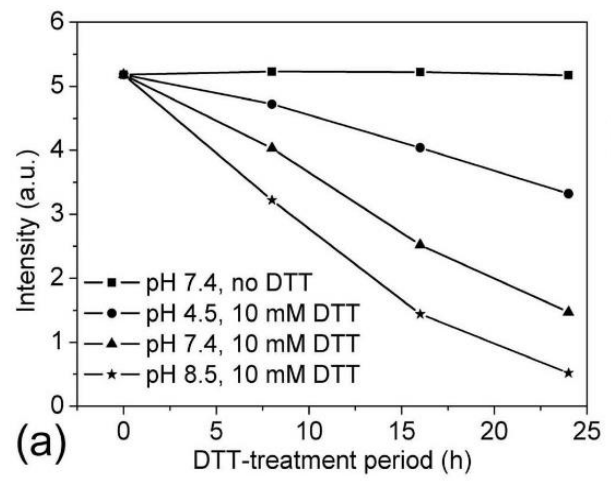




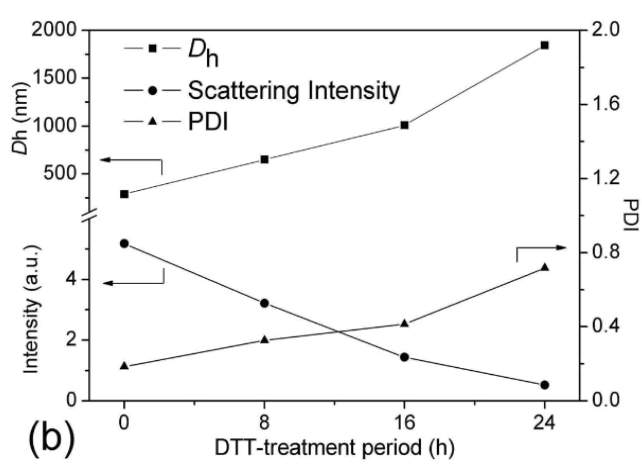

Fig. 6 Evolution of scattering intensity of the crosslinked nanogels AM01 aqueous solution $(0.05 \mathrm{wt} \%)$ during the DTT-treatment $(10 \mathrm{mM})$ at different $\mathrm{pH}$ values at $37^{\circ} \mathrm{C}(\mathrm{a})$, and plotting of scattering intensity, $D_{\mathrm{h}}$ and 5 PDI against the DTT-treatment period $(10 \mathrm{mM}, \mathrm{pH} 8.5)$ for the crosslinked nanogels AM01 aqueous solution $(0.05 w t . \%)$; the solid lines just serve as eye guidance.

Additionally, it is of interest to note that DCL nanogels containing thiol groups still retain the ${ }_{10}$ thermo-responsive character. As shown in Fig. 4, upon heating, thermo-induced micelles were observed again within the DCL nanogels solution $(0.05 w t . \%)$ at $50^{\circ} \mathrm{C}$, and a slightly larger $D_{\mathrm{h}}(280 \mathrm{~nm}$, PDI 0.11$)$ was observed, compared with that for the physicallyis assembled micelles (non-CL nanogels, $240 \mathrm{~nm}$, PDI $0.05)$. This difference might be attributed to the presence of thiol side-groups along the PVOH block after DTT-treatment, which is expected to affect the macromolecular chain hydrophilicity and ${ }_{20}$ configuration of the PVOH block, according to a previous report. ${ }^{45}$ Moreover, thiol groups were reported to be easily oxidized into disulfide bonds by some oxidative reagents, such as $\mathrm{Fe}^{3+}$, hydrogen peroxide, oxygen, etc. ${ }^{46,47}$ Herein, the reversibility of ${ }_{25}$ the crosslinking was also tested by adding $\mathrm{H}_{2} \mathrm{O}_{2}$ solution (30wt.\%) into the solution of DCL nanogels at $50^{\circ} \mathrm{C}(0.05 \mathrm{wt} . \%)$. Nanogels particles were detected again by DLS analysis with average $D_{\mathrm{h}}$ of $380 \mathrm{~nm}$ (PDI 0.28 ) at $25^{\circ} \mathrm{C}$ (Fig. 4), a little bit larger than the former ${ }_{30}$ crosslinked nanogels $\left(D_{\mathrm{h}} 280 \mathrm{~nm}\right.$, PDI 0.17), which might be attributed to the lower crosslinking degree upon re-crosslinking, thereby higher swelling after cooling down below the VPTT. Furthermore, TEM image (See ESI, Fig. S5d†) and Raman spectra (Fig. 1, ${ }_{35} \mathrm{~S}-\mathrm{S}$ bonds) also evidenced the formation of recrosslinked (RCL) nanogels, suggesting reversibility of the crosslinking.

\section{Model studies on guest loading of Nile red and triggered} release behaviours

${ }_{40}$ The reversibly crosslinked nanostructures could impart the those micelles or nanogels with great potential as DDS, since they are capable of effectively trapping the drug payloads within the microenvironment, while triggered release could be ${ }_{45}$ accomplished by the external stimuli. ${ }^{7,8,36}$ To explore the potential of PVOH- $b$-PNVCL reversiblycrosslinked nanogels as DDS, Nile red, a hydrophobic dye, was chosen as a model drug and loaded into the hydrophobic PNVCL domain above the LCST ${ }_{50}$ (Scheme 1). It has been reported that fluorescence emission of $\mathrm{NR}$ is negligible in aqueous solution due to its weak solubility $\left(<1 \mu \mathrm{g} / \mathrm{mL}, 25^{\circ} \mathrm{C}\right)$; however, it increases substantially in a hydrophobic environment. ${ }^{41}$ Stable nanogels aqueous dispersion ${ }_{s s}$ with red luminance was obtained after the loading of NR (See ESI, Fig. S6b $†$ ), while transparent solution without NR loaded was observed for crosslinked nanogels solution (See ESI, Fig. S6a†). Spherical nanogels were observed again from the TEM image of ${ }_{60}$ the NR-loaded crosslinked nanogels AM01 (See ESI, Fig. S6c $\dagger$ ), and a slight increase in $D_{\mathrm{h}}$ was observed from 290 to $300 \mathrm{~nm}$ for NR-loaded AM01, due to the presence of NR (See ESI, Fig. S7 $\uparrow$ ). The drug loading capacity (mass ratio of NR loaded to nanogels) was ${ }_{65}$ spectrophotometrically estimated to be $c a .1 .9 \mathrm{wt} . \%$ and drug loading efficiency (mass ratio of NR loaded to NR fed) of $48 \%$, comparable to the loading capability of another disulfide-crosslinked nanogels as DDS, as reported by Du and $\mathrm{Li}^{22}$

70 Release profiles of NR from the NR-loaded PVOH$b$-PNVCL nanogels were traced by following the change in NR fluorescence intensity over a period of $24 \mathrm{~h}$ under different conditions. Fig. 7a shows the typical release profiles of NR from AM01 at $37^{\circ} \mathrm{C}$ with ${ }_{75}$ or without $10-\mathrm{mM}$ DTT at different $\mathrm{pH}$ values. It was found that, without DTT, release below $8 \%$ was detected over this period in spite of different $\mathrm{pH}$ values, indicating a stable trapping of NR within the crosslinked nanogels. However, in the presence of 10${ }_{80} \mathrm{mM}$ DTT, a release of $c a .72 \%$ at $\mathrm{pH} 7.4$ and $c a .80 \%$ at $\mathrm{pH} 8.5$ can be accomplished after 24-h release, while only $c a .50 \%$ at $\mathrm{pH} 4.5$ was obtained. This is in agreement with preferable cleavage of disulfide bonds under basic conditions, as revealed in Fig. 6a. It might, ${ }_{85}$ however, be conjectured that the different release behaviours result from the different solubility of NR in those buffers. To justify or deny this hypothesis, the solubility of NR in different buffers was checked by dispersing $1 \mathrm{mg}$ of NR in $1 \mathrm{~mL}$ of buffer solutions with ${ }_{90} \mathrm{pH}$ of 4.5 (NaAc/HAc), 7.4 (PBS) and 8.5 (PBS), respectively. After removing the precipitated NR, the supernatant solution was checked with a fluorometer, and fluorescence emission intensity at $595 \mathrm{~nm}$ (Ex: $485 \mathrm{~nm}$ ) was 237, 251 and 266, respectively, while for ${ }_{95}$ the NR-loaded crosslinked nanogels AM01, the fluorescence intensity was higher than 25,000. This confirmed that the solubility of NR in water was not affected by $\mathrm{pH}$, in agreement with the previous report. ${ }^{42}$ This time-dependent release behaviour 100 strongly supports that the drug release was indeed resulted from cleavage of disulfide bonds, rather than the effect from diffusion, osmotic pressure, or even improved solubility under different $\mathrm{pH}$ values, etc. Furthermore, the incomplete release even in basic 10s conditions might be explained by the incomplete 
dissociation of the nanogels and unavoidable oxidation of thiol groups to disulfide bonds by ambient $\mathrm{O}_{2}$, as some nanogels could still be detected in Fig. 4 and ESI, Fig. S5a†.

To elucidate the effect of the composition as well as LCST of the PVOH- $b$-PNVCL copolymers on the release behaviours, NR was also attempted to be loaded within the nanogels AM02, which were prepared from $\mathrm{PVOH}_{226}-b$-PNVCL 494 copolymer with ${ }_{10} \mathrm{LCST}$ of $37^{\circ} \mathrm{C}$. A higher loading capacity $(2.5 w t . \%)$ and efficiency $(62 \%)$ of NR were obtained above the LCST, due to the larger hydrophobic PNVCL domains, as well as larger size $\left(D_{\mathrm{h}}\right.$ of $\left.460 \mathrm{~nm}\right)$. The release behaviours were also followed in the presence 15 or not of DTT (10 mM, pH 8.5). As shown in Fig. 7b, similarly to the release behaviours of AM01, very small amount of NR was released in the absence of DTT. However, as expected, the release was accelerated when exposed to DTT. It should be noted ${ }_{20}$ that this release was very low $(36 \%)$ after $24-\mathrm{h}$ DTT treatment, compared to $80 \%$ for AM01 in Fig. 7a under the same condition. To explain the difference between these two release profiles, DLS was used to check the size distribution of the NR-loaded crosslinked 25 nanogels solutions at $37^{\circ} \mathrm{C}$ after $24-\mathrm{h}$ DTT treatment, with the released NR removed. As shown in ESI, Fig. S7a $\uparrow$, a sharp decrease in scattering intensity (proportional to the amount of nanogels) and wide size distribution was detected for AM01 after 24-h DTT 30 treatment, similar to the size distribution profile of AM01 DCL nanogels (Fig. 4) after 24-h 10-mM DTT treatment. However, the amount of nanogels seems to be not affected too much for AM02 (See ESI, Fig. $\mathrm{S} 7 \mathrm{~b} \dagger)$. It is probably because of the lower LCST of ${ }_{35} 37^{\circ} \mathrm{C}$ for $\mathrm{PVOH}_{226}-b$ - $\mathrm{PNVCL}_{494}$ copolymer, which resulted in the intact micellar structure at $37^{\circ} \mathrm{C}$, even after the cleavage of crosslinking structures. The micellar structures at $37^{\circ} \mathrm{C}$ were also evidenced by DLS in the thermo-responsiveness studies of ${ }_{40} \mathrm{PVOH}_{226}-b$-PNVCL 494 (See ESI, Fig. S2 $\uparrow$ ). Therefore, for the nanogels with LCST below or near $37^{\circ} \mathrm{C}$, the remaining NR was still trapped within the nanogels, resulting in a retarded release even after the decrosslinking (Scheme 1).

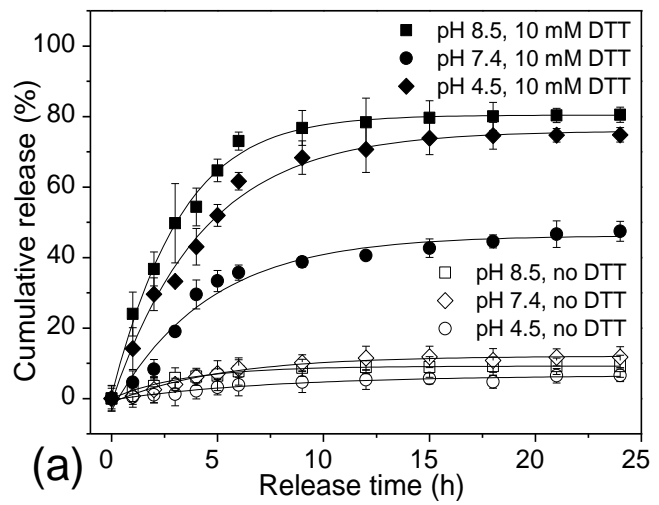

45

(a) Release time (h)

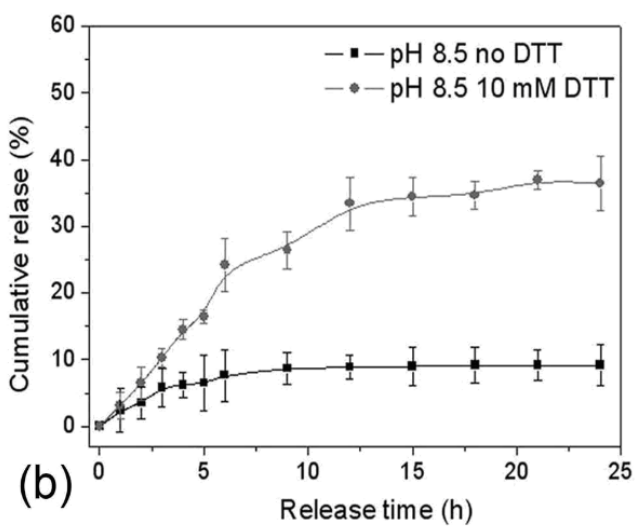

Fig. 7 Plotting of cumulative release $v s$. release time of NR from the NRloaded PVOH- $b$-PNVCL crosslinked nanogels AM01 within buffers solutions with different $\mathrm{pH}$ values, with or without $10-\mathrm{mM}$ DTT at $37^{\circ} \mathrm{C}$ 50 (a); and release profiles of NR from NR-loaded PVOH- $b$-PNVCL crosslinked nanogels $\mathrm{AM} 02$ at $37^{\circ} \mathrm{C}$ at $\mathrm{pH}$ of 8.5 with or without $10-\mathrm{mM}$ DTT (b). The solid lines just serve as eye guidance.

Cytotoxicity assessment and cellular uptake of the crosslinked nanogels

${ }_{55}$ Covalently-crosslinked micelles or nanogels exhibit improved stability compared to those non-crosslinked micelles during the in vivo delivery, leading to minimal premature release if used for DDS.8 However, the chemical crosslinking also raises ${ }_{60}$ increasing concerns on the potential toxicity of those covalent crosslinking residuals or the unexpected side effects with drugs loaded during the chemical crosslinking reaction. Cytotoxicity of the PVOH- $b$ PNVCL crosslinked nanogels against mouse ${ }_{65}$ fibroblast-like L929 cell line was evaluated via the MTS assay. To exclude the interference of PVOH- $b$ PNVCL nanogels themselves on the absorbance of formazan product at $490 \mathrm{~nm}$, we recorded the UV/vis absorption spectra of the parent copolymer and the 70 resultant nanogels solution $(0.1 w t . \%)$ in ESI, Fig. S8 $\dagger$, and the absorbance at $490 \mathrm{~nm}$ is both below 0.005 (a.u.). Furthermore, we also measured the UV/vis absorbance of the mixture of $100 \mu \mathrm{L}$ of nanogels solution in PBS buffer $(0.1 w t . \%)$ and $20 \mu \mathrm{L}$ of MTS 75 at $490 \mathrm{~nm}$, and an averaged value of $c a .0 .008$ from five independent samples, comparing to the value $c a$. 0.554 for those untreated cells. Thus, it justifies that the use of MTS assay to evaluate the PVOH- $b$-PNVCL nanogels was feasible and presence of PVOH- $b$ ${ }_{80}$ PNVCL nanogels will not disturb the absorbance of the final formazan product. The cells were treated with crosslinked nanogels AM01 and AM02 with different incubation concentrations for different periods, while non-treated cells were taken as a control $(100 \%$ ${ }_{85}$ viability). As shown in Fig. 8a and $8 b$, both two nanogels exhibit high cell viability over $85 \%$, even after 48-h incubation even with concentrated nanogels solution $(2 \mathrm{mg} / \mathrm{mL})$. The slight effect on the cell viability and cell proliferation capability might suggest ${ }_{90}$ low cytotoxicity for these crosslinked nanogels, as well as the crosslinking nanostructures. 

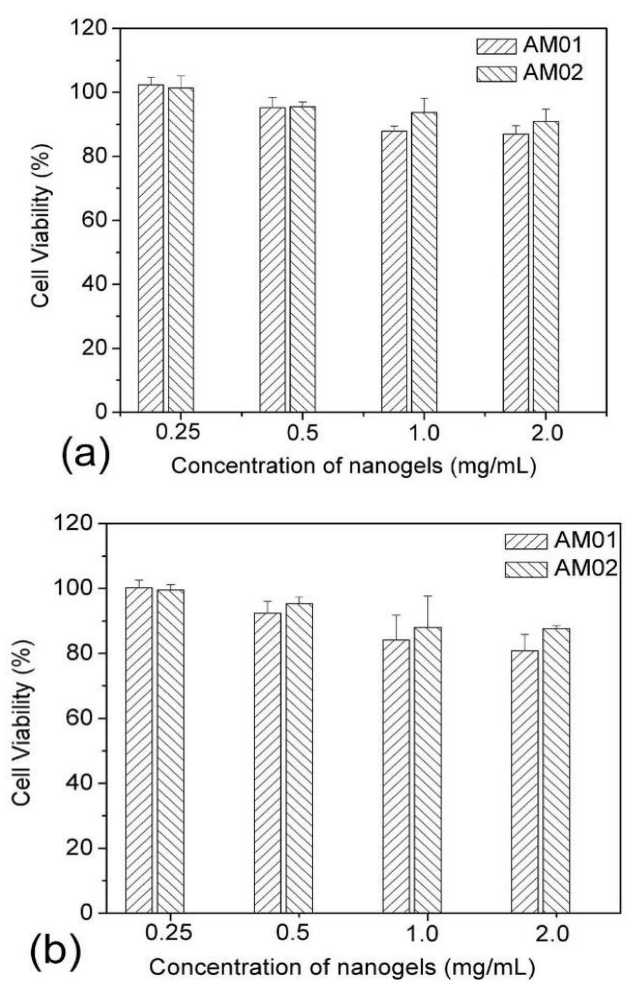

Fig. 8 Cytotoxicity profiles of the PVOH- $b$-PNVCL crosslinked nanogels AM01 and AM02 against the mouse fibroblast-like L929 cell line as a 5 function of nanogels concentration after 24-h (a) and 48-h incubation (b), respectively; percentage cell viabilities of the L929 cells were expressed relatively to the un-treated cells (control, $100 \%$ viability). Results are presented as mean value \pm standard deviation $(n=5)$.

Generally, the enhanced efficiency of disease 10 treatment could be achieved via higher drug release efficiency and/or efficient uptake of the drug-loaded DDS. Here, the cellular uptake of the NR-loaded crosslinked nanogels AM01 into the human melanoma MEL-5 cells could be directly visualized by 15 fluorescence microscopy (Fig. 9a), with NR as a fluorescence probe. Red fluorescence could be observed only in the cytoplasm of MEL-5 cells other than nuclei (blue) after 24-h incubation with the NRloaded PVOH-b-PNVCL crosslinked nanogels ${ }_{20}(\mathrm{AM} 01,0.25 \mathrm{mg} / \mathrm{mL})$, while the non-treated MEL-5 cells did not exhibit any red fluorescence of Nile red (See ESI, Fig. S9†). Fluorescence-activated cell sorting (FACS) technique was also used to characterize the treated MEL-5 cells, while un-treated ${ }_{25}$ cells were taken as blank. It is obvious to see two totally different cell populations in Fig. 9b-1 and Fig. 9b-2, with a big shift in the histograms in Fig. 9b-3, and also sharp increase in fluorescence intensity, as listed in Fig. 9b-4. These FACS results also ${ }_{30}$ corroborate the cellular uptake of the crosslinked nanogels, which is a prerequisite for the intracellular DDS. Furthermore, quantitative studies on the cellular uptake were carried out with the FACS results. Mean fluorescence intensity (MFI), which was denoted as ${ }_{35}$ the ratio of fluorescence intensity per 10,000 treated

cells to that of 10,000 un-treated cells, was used as an indirect measure to evaluate the cellular uptake efficiency. This approach has also been used to assess the uptake of some drugs ${ }^{50}$ and gene delivery ${ }_{40}$ vehicles, ${ }^{51}$ etc. Here, MFI was plotted against the incubation period as well as incubation concentration in Fig. 9c-1 and Fig. 9c-2, respectively. As shown, a faster increase in MFI was observed within the first 15 $\mathrm{h}$, while a slight increase afterward. A dose-dependent ${ }_{45}$ cellular uptake was also detected when the incubation concentration of crosslinked nanogels was increased, suggesting the possibility of manipulation of cellular uptake efficiency of the PVOH- $b$-PNVCL crosslinked nanogels via control over the incubation concentration ${ }_{50}$ or/and incubation period.

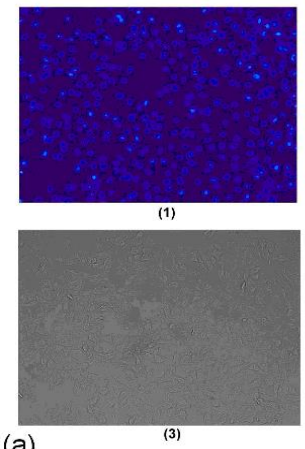

(a)
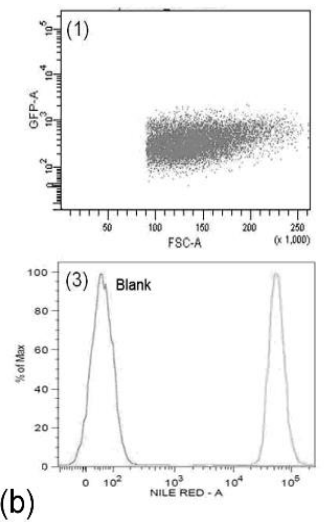

(b)

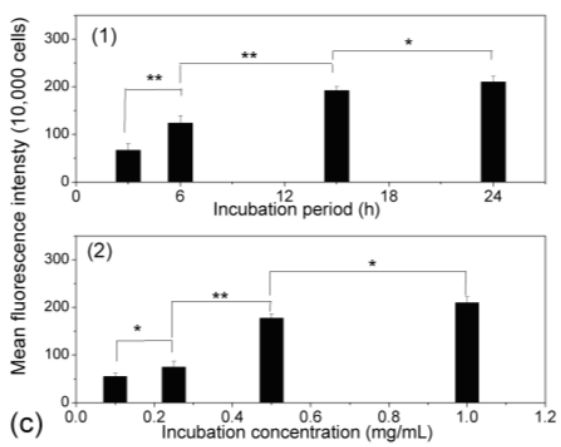

${ }_{55}$ Fig. 9 (a): Fluorescence microscopic images of the treated MEL-5 cells after 24-h incubation with the NR-loaded PVOH- $b$-PNVCL crosslinked nanogels AM01 (0.25 mg/mL): (1) nuclei stained with DAPI (blue), (2) fluorescence pattern of NR (red), (3) contrast field pattern, (4) merged images of (1), (2) and (3), scale bar: $100 \mu \mathrm{m}$; (b): FACS diagrams of (1) 60 untreated MEL-5 cells, (2) treated MEL-5 cells after 24-h incubation with 
NR-loaded crosslinked nanogels AM01 $(0.25 \mathrm{mg} / \mathrm{mL})$, (3) plotting of the number of cells (counts on $y$-axis) against the log of fluorescence intensity (Nile Red-A on $x$-axis) and (4) FACS analysis results; (c): (c-1) dependence of the MFI of the treated MEL-5 cells on incubation period 5 after incubation with NR-loaded crosslinked nanogels AM01 (3, 6, 15 and $24 \mathrm{~h}, 0.25 \mathrm{mg} / \mathrm{mL}$ ), and (c-2) dependence of the MFI of the treated MEL-5 cells on the incubation concentration after 15-h incubation with NR-loaded crosslinked nanogels AM01 $(0.1,0.25,0.5$ and $1.0 \mathrm{~g} / \mathrm{L})(* * P<0.05$, ** $=$ $P<0.01$ by the Student' $t$-test, $\mathrm{n}=3$ ).

\section{${ }_{10}$ Conclusions}

In this study, reversibly-crosslinked thermo- and redox-responsive PVOH-b-PNVCL nanogels were fabricated with disulfide-bearing crosslinking reagent 3,3'-dithiodipropionic acid. Their spherical shape was 15 confirmed by TEM, with Dh of ca. $280 \mathrm{~nm}$ (PDI 0.17). Good colloidal stability against heating was confirmed above the VPTT, with a slight shrinkage rather than inter-particles agglomeration. Compared to noncrosslinked micelles, only a slight swelling of the ${ }_{20}$ crosslinked nanogels was observed against water dilution below the VPTT, which is critical to the success of zero premature drug release upon intravenous injection. However, the crosslinked nanogels can be easily dissociated in a reductive ${ }_{25}$ environment thanks to the redox-sensitive crosslinking structures, so that the drug release could be triggered intracellularly. Interestingly, the de-crosslinked copolymers (bearing free thiols along the $\mathrm{PVOH}$ block) can be crosslinked again by exposure to ${ }_{30}$ oxidative agent, such as $\mathrm{H} 2 \mathrm{O} 2$, above the LCST. Hydrophobic model drug (NR) could be easily loaded into the crosslinked nanogels, while cleavage of the disulfide bonds can effectively trigger the drug release (80\% drug release in presence of $10-\mathrm{mM}$ DTT while 35 only $8 \%$ without DTT in $24 \mathrm{~h}$ ). This specific redoxresponsive property might also facilitate the release of the loaded drugs within the cytoplasm in response to glutathione $(10 \mathrm{mM})$. In addition, we also disclosed that the use of PVOH-b-PNVCL copolymer exhibiting

${ }_{40} \mathrm{a} \mathrm{LCST}$ above $37^{\circ} \mathrm{C}$ was preferable, with a fast release upon exposure to DTT-treatment under physiological condition. Cytotoxicity studies disclosed a low toxicity and good biocompatibility with mouse fibroblast-like L929 cell line for the crosslinked ${ }_{45}$ nanogels. Moreover, the crosslinked nanogels can easily internalize within the human melanoma MEL-5 cells. Incubation concentration- and period-dependent cellular uptake was also detected for these PVOH-bPNVCL crossliniked nanogels. This kind of ${ }_{50}$ crosslinked nanogels is thus promising for the triggered delivery of hydrophobic drugs for intracellular release.

\section{Acknowledgements}

The authors thank the Belgian National Funds for ${ }_{55}$ Scientific Research (F.R.S.-FNRS), the European Community in the frame of the Erasmus Mundus International doctoral school IDS-FunMat and the
Science Policy Office of the Belgian Federal Government (PAI VII-05) for their financial support. ${ }_{60}$ The authors are also grateful to the GIGA-imaging and flow cytometry platform in University of Liège for their help with CLSM and flow cytometry measurement. C.D. and A.D. are Research Director and Research Associate by F.R.S-FNRS, respectively.

\section{${ }_{65}$ Notes and references}

${ }^{a}$ Center for Education and Research on Macromolecules (CERM), University of Liege, B6 Sart Tilman, B-4000 Liège, Belgium. Fax: (32)436663497; Tel: (32)4-3663565; c.jerome@ulg.ac.be,

christophe.detrembleur@ulg.ac.be

$70{ }^{b}$ Laboratory of Mammalian Cell Culture (GIGA-R), University of Liège, B6 Sart Tilman, B-4000 Liege, Belgium

${ }^{c}$ CNRS, Univ. Bordeaux, ICMCB, UPR 9048, F-33600 Pessac, France

$\dagger$ Electronic Supplementary Information (ESI) available: SEM of the 75 crosslinked nanogels AM01, TEM of the de-crosslinked nanogels and recrosslinked nanogels AM01, picture of the crossliniked nanogels AM01 aqueous solution $(0.05 w t . \%)$ with or without NR loaded, size distribution diagrams of the NR-loaded crossliniked nanogels AM01 before and after DTT-treatment, UV/vis spectra of the crosslinked nanogels solution $(0.1$ $80 w t . \%)$ and parent PVOH- $b$-PNVCL copolymer solution $(0.1 w t . \%)$, etc. See DOI: $10.1039 / \mathrm{b} 000000 \mathrm{x} /$

1. J. C. Leroux and A. Vintiloiu, J Control Release, 2008, 125, 179-192.

2. S. Kim, Y. Shi, J. Y. Kim, K. Park and J. X. Cheng, Expet Opin Drug Deliv, 2010, 7, 49-62.

3. X. B. Xiong, A. Falamarzian, S. M. Garg and A. Lavasanifar, J Control Release, 2011, 155, 248-261.

4. C. Deng, Y. J. Jiang, R. Cheng, F. H. Meng and Z. Y. Zhong, Nano Today, 2012, 7, 467-480.

90 5. M. Talelli and W. E. Hennink, Nanomedicine, 2011, 6, 1245-1255.

6. Y. Shao, W. Huang, C. Shi, S. T. Atkinson and J. Luo, Ther Deliv, 2012, 3, 1409-1427.

7. M. Amiji, S. Ganta, H. Devalapally and A. Shahiwala, J Control Release, 2008, 126, 187-204.

95 8. R. K. O'Reilly, C. J. Hawker and K. L. Wooley, Chem Soc Rev, 2006, 35, $1068-1083$.

9. S. P. Armes and E. S. Read, Chem Commun, 2007, 29, 3021-3035.

10. J. O. You, M. Rafat and D. T. Auguste, Langmuir, 2011, 27, $11282-$ 11286.

100 11. H. Gao, M. C. Jones, J. Chen, R. E. Prud'homme and J. C. Leroux, Chem Mater, 2008, 20, 3063-3067.

12. Z. Zhou, G. Liu and L. Hong, Biomacromolecules, 2011, 12, 813-823.

13. M. H. Stenze, L. Zhang, W. G. Liu, L. Lin and D. Y. Chen, Biomacromolecules, 2008, 9, 3321-3331.

105 14. K. Kataoka, Y. Kakizawa and A. Harada, J Am Chem Soc, 1999, 121, $11247-11248$.

15. R. Cheng, F. Feng, F. Meng, C. Deng, J. Feijen and Z. Zhong, J Control Release, 2011, 152, 2-12.

16. A. Gopferich, S. Bauhuber, C. Hozsa and M. Breunig, Adv Mater, 2009, $110 \quad$ 21, 3286-3306.

17. W. F. Dong, A. Kishimura, Y. Anraku, S. Chuanoi and K. Kataoka, $J$ Am Chem Soc, 2009, 131, 3804-+.

18. S. Y. Liu, J. Y. Zhang, X. Jiang, Y. F. Zhang and Y. T. Li, Macromolecules, 2007, 40, 9125-9132.

115 19. S. Cajot, N. Lautram, C. Passirani and C. Jerome, J Control Release, 2011, 152, 30-36.

20. Y. Li, K. Xiao, J. Luo, W. Xiao, J. S. Lee, A. M. Gonik, J. Kato, T. A. Dong and K. S. Lam, Biomaterials, 2011, 32, 6633-6645.

21. A. P. Zhang, Z. Zhang, F. H. Shi, J. X. Ding, C. S. Xiao, X. L. Zhuang, C. L. He, L. Chen and X. S. Chen, Soft Matter, 2013, 9, 2224-2233.

22. Z. Y. Qiao, R. Zhang, F. S. Du, D. H. Liang and Z. C. Li, J Control Release, 2011, 152, 57-66.

23. J. Kato, Y. Li, K. Xiao, J. S. Lee, J. Luo, J. M. Tuscano, R. T. O'Donnell and K. S. Lam, Mol Pharmaceut, 2012, 9, 1727-1735. 
24. H. Sun, B. Guo, X. Li, R. Cheng, F. Meng, H. Liu and Z. Zhong, Biomacromolecules, 2010, 11, 848-854.

25. C. Detrembleur, R. Bryaskova, N. Willet, A. S. Duwez, A. Debuigne, L. Lepot, B. Gilbert, C. Jerome and R. Jerome, Chem-Asian J, 2009, 4, 1338-1345.

26. R. Jerome, R. Bryaskova, N. Willet, A. Debuigne and C. Detrembleur, J Polym Sci Pol Chem, 2007, 45, 81-89.

27. R. Bryaskova, D. Pencheva, M. Kyulavska, D. Bozukova, A. Debuigne and C. Detrembleur, J Colloid Interf Sci, 2010, 344, 42410428.

28. C. Detrembleur, A. Debuigne, N. Willet and R. Jerome, Macromolecules, 2007, 40, 7111-7118.

29. M. Hurtgen, C. Detrembleur, C. Jerome and A. Debuigne, Polym Rev, 2011, 51, 188-213.

15 30. M. Hurtgen, J. Liu, A. Debuigne, C. Jerome and C. Detrembleur, $J$ Polym Sci Pol Chem, 2012, 50, 400-408.

31. X. Z. Zhang, H. Wei, C. Y. Quan, C. Chang and R. X. Zhuo, J Phys Chem B, 2010, 114, 5309-5314.

32. X. Z. Zhang, H. Wei, D. Q. Wu, Q. Li, C. Chang, J. P. Zhou and R. X. 20 Zhuo, J Phys Chem C, 2008, 112, 15329-15334.

33. S. Y. Liu, Y. M. Zhou, K. Q. Jiang and Y. Q. Chen, J Polym Sci Pol Chem, 2008, 46, 6518-6531.

34. X. Z. Zhang, H. Wei, C. Cheng, C. Chang, W. Q. Chen, S. Cheng and R. X. Zhuo, Langmuir, 2008, 24, 4564-4570.

25 35. R. Hoogenboom, H. M. Thijs, M. J. Jochems, B. M. van Lankvelt, M. W. Fijten and U. S. Schubert, Chem Commun, 2008, 44, 5758-5760.

36. H. Wei, S.-X. Cheng, X.-Z. Zhang and R.-X. Zhuo, Prog Polym Sci, 2009, 34, 893-910.

37. A. E. Smith, X. Xu and C. L. McCormick, Prog Polym Sci, 2010, 35, 45-93.

38. A. Debuigne, R. Poli, C. Jerome, R. Jerome and C. Detrembleur, Prog Polym Sci, 2009, 34, 211-239.

39. T. Kissel, X. T. Shuai, T. Merdan, A. K. Schaper and F. Xi, Bioconjugate Chem, 2004, 15, 441-448.

35 40. Q. Huo, J. Liu, L. Q. Wang, Y. Jiang, T. N. Lambert and E. Fang, J Am Chem Soc, 2006, 128, 6447-6453.

41. G. Gaucher, M. H. Dufresne, V. P. Sant, N. Kang, D. Maysinger and J. C. Leroux, J Control Release, 2005, 109, 169-188.

42. A. L. Weikel, S. G. Owens, T. Fushimi and H. R. Allcock, 40 Macromolecules, 2010, 43, 5205-5210.

43. X. Zhang, J. Niu, F. Shi, Z. Liu and Z. Q. Wang, Langmuir, 2007, 23, 6377-6384.

44. S. Matsumoto, R. J. Christie, N. Nishiyama, K. Miyata, A. Ishii, M. Oba, H. Koyama, Y. Yamasaki and K. Kataoka, Biomacromolecules, 2009, 10, 119-127.

45. A. Eisenberg and T. Azzam, Angew Chem Int Et, 2006, 45, 7443-7447.

46. J. Y. Zhang, X. Jiang, Y. F. Zhang, Y. T. Li and S. Y. Liu, Macromolecules, 2007, 40, 9125-9132.

47. C. L. McCormick, X. W. Xu and A. E. Smith, Aust J Chem, 2009, 62, 1520-1527.

48. M. C. A. Stuart, J. C. van de Pas and J. B. F. N. Engberts, J Phys Org Chem, 2005, 18, 929-934.

49. D. L. Sackett and J. Wolff, Anal Biochem, 1987, 167, 228-234.

50. J. M. Rosenholm, A. Meinander, E. Peuhu, R. Niemi, J. E. Eriksson, C. Sahlgren and M. Linden, ACS Nano, 2009, 3, 197-206.

51. P. Vader, L. J. van der Aa, J. F. Engbersen, G. Storm and R. M. Schiffelers, J Control Release, 2010, 148, 106-109.

\section{${ }_{60}$ Graphical abstract}

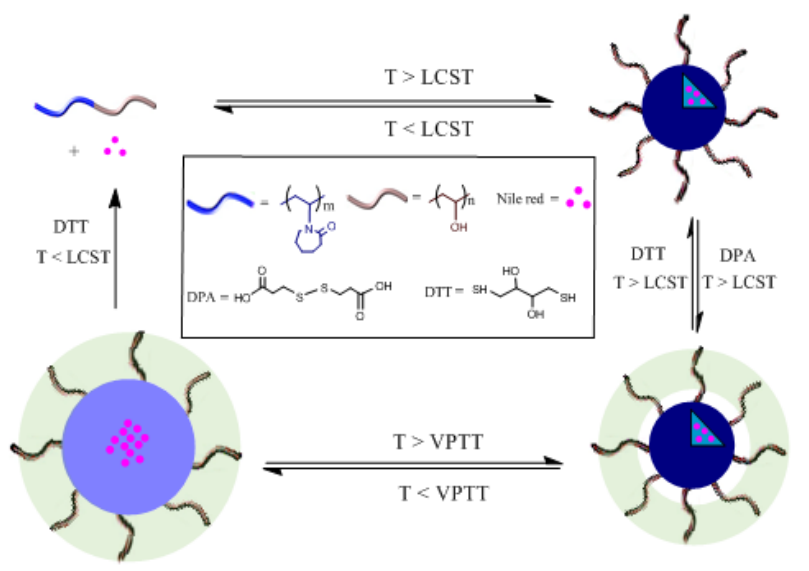

Reversible crosslinked thermo- and redox-responsive PVOH- $b$ PNVCL nanogels designed for controlled drug release 